\title{
Pengelolaan Keuangan Yang Akuntabel Pada Lembaga Amil Zakat Azka Jember
}

\author{
Munir Is'adi, Nur Ika Mauliyah \\ Prodi Akuntansi Syariah UIN KH Achmad Siddiq Jember \\ Email: Munirisadi@uinkhas.ac.id, nurikamauliyah@uinkhas.ac.id
}

\begin{abstract}
community service program aims to provide mentoring the leaders as organizational policy makers and also implementers of operational activities to to carry out internal supervision, especially for employee able to prepare and present accountable financial reports it's PSAK 109 concerning zakat accounting and infaq/sedekah. The mentoring method used conduct discussions by presenting about PSAK 109, then reviewing of financial statements and made and working on financial reports in accordance with PSAK 109 with assistance for the 2020 financial reporting period.
\end{abstract}

Key word : Financial Report, PSAK 109, LAZ

\begin{abstract}
Abstrak
Program pengabdian kepada masyarakat ini memiliki tujuan memberikan pendampingan kepada pengambil kebijakan organisasi dalam hal ini adalah pimpinan dan juga pelaksana kegiatan operasional sehingga diharapkan pengawasan internal dapat dilakukan oleh seluruh pengurus terutama bagi pelaksana harian diharapkan mereka mampu menyajikan laporan keuangan yang akuntanbel sebagaimana tertuang dalam PSAK 109 tentang akuntansi zakat dan infak/sedekah. Metode pelaksanaan program kemitraan atau pendampingan ini membentuk forum diskusi dengan menyampaikan materi tentang PSAK 109, kemudian mengkaji laporan keuangan yang telah dibuat dan mngerjakan kembali laporan keuangan yang disesuaikan PSAK 109 dengan pendampingan data laporan keuangan Tahun 2020.
\end{abstract}

Kata Kunci : Laporan Keuangan, PSAK 109, Lembaga Amil Zakat

\section{Pendahuluan}

Dalam perkembangannya akuntansi tidak hanya digunakan pada organisasi laba melainkan juga nirlaba. Hal ini terlihat bahwa informasi keuangan sangat dibutuhkan pada setiap aspek perekonomian atau bisnis. Begitupun dengan organisasi nirlaba juga membutuhkan laporan keuangan sebagai informasi keberlajutan organisasi.

Lembaga Amil Zakat merupakan organisasi nirlaba yang dibentuk masyarakat yang memiliki tugas membantu pengumpulan, pendistribusian dan pendayagunaan zakat sebagaimana tertuang dalam UU no.23 tahun 2011. Begitupun Lembaga Amil Zakat AZKA Jember yang dibentuk berdasarkan SK bupati No. 103 TAhun 2004. Dibentukkan LAZ AZKA ini dengan tujuan untuk memudahkan para muzaki dalam menunaikan kewajiban zakat yang sesuai kaidah 
agama. Selain itu juga diharapkan adanya penyaluran zakat yang tepat sasaran dan berdaya guna dalam memberdayakan masyarakat.

Laporan keuangan merupakan salah satu bentuk Akuntabilitas organisasi pengelola zakat, karena berisikan informasi yang dibutuhkan oleh pihak yang berkepentingan baik dari internal maupun eksternal. Maka dari itu diperlukannya penyajian laporan keuangan yang akuntabel dalam hal ini sesuai dengan PSAK 109 yakni pernyataan standart akuntansu keuangan tentang zakat dan infaq/sedekah. Selama ini LAZ AZKA masih menyajikan laporan keuangan dengan format yang seadanya belum sesuai dengan standart sebagaimana terlihat dalam tabel dibawah ini :

\begin{tabular}{|c|c|c|c|c|c|c|c|c|c|c|c|c|c|c|c|c|c|}
\hline \multicolumn{18}{|c|}{ DAFTAR PENERIMAAN DANA ZISKAF } \\
\hline \multicolumn{18}{|c|}{ YAYASAN AZKA AL BAITUL AMIEN JEMBER } \\
\hline \multicolumn{18}{|c|}{ TAHUN 2020} \\
\hline \multirow{3}{*}{ NO } & \multirow{3}{*}{ U R A I A N } & \multirow{3}{*}{\begin{tabular}{|c|} 
NO.KODE \\
Rekening \\
\end{tabular}} & \multirow{2}{*}{\multicolumn{6}{|c|}{ BULAN }} & & & & & & & & & \\
\hline & & & & & & & & & \multirow{2}{*}{$\begin{array}{c}\text { SUB } \\
\text { JUMLAH } \\
\end{array}$} & \multicolumn{6}{|c|}{ BULAN } & \multirow{2}{*}{$\begin{array}{c}\text { SUB } \\
\text { JUMLAH }\end{array}$} & \multirow{2}{*}{\begin{tabular}{|c|} 
JUMLAH \\
Keseluruhan \\
\end{tabular}} \\
\hline & & & JAN & PEB & MAR & APRII & MEI & JUNI & & JULI & AGUST & SEP & ОКТОВ & NOP & DES & & \\
\hline 1 & Zakat Maal & & 2000 & $\mathrm{xox}$ & $x 0 x$ & $x 00 x$ & $x 00 x$ & $x 0 x x$ & $\begin{array}{r}- \\
\end{array}$ & $x 00$ & $x 00$ & $x 00$ & $x 0 x$ & $x 00$ & $x 00 x$ & - & \\
\hline 2 & Zakat Fitrah & & $x 00 x$ & $x 00$ & $x 00 x$ & $x 00$ & $x 0 x$ & $x 00$ & - & $x 00$ & $x 00 x$ & $x 00 x$ & $x 00$ & $x 00 x$ & $x 00 x$ & - & 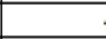 \\
\hline 3 & \multicolumn{2}{|c|}{ Infaq dan Shadaqah } & $x 00$ & $x 00 x$ & $x 0 x$ & $x 00 x$ & $x 00 x$ & $x x x$ & - & $100 x$ & $x 00 x$ & $100 x$ & $x 00 x$ & $x 00 x$ & $x 00 x$ & - & 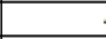 \\
\hline 4 & Fidyah & & $x 00$ & $x x x$ & $x 0 x x$ & $x 0 x$ & $x 0 x x$ & $x x x$ & - & $x 00$ & $x 00 x$ & $x 00 x$ & $x 00 x$ & $x 0 x$ & $x 00 x$ & - & . \\
\hline 5 & \multicolumn{2}{|c|}{ Dompet Dhuafa } & $x 00 x$ & $x 0 x$ & $x 0 x$ & $x 0 x$ & $x 0 x$ & $x 0 x$ & - & $x 00 x$ & $x 00 x$ & $x 00$ & $x 00 x$ & $x 00 x$ & $x 00 x$ & - & 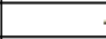 \\
\hline 6 & \multicolumn{2}{|c|}{ Peduli Anak Yatim } & $x 00$ & $x 00$ & $x 0 x$ & $x 0 x$ & $x x x$ & $x x x$ & - & $x 00$ & $x 00 x$ & $x 00 x$ & $x 0 x$ & $x 0 x$ & $x 0 x$ & - & . \\
\hline 7 & \multicolumn{2}{|c|}{ Beasiswa Pendidikan } & 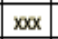 & $x 0 x$ & $x x x$ & $x 0 x$ & $x x x$ & $x x x$ & - & $x 00$ & $x 0 x$ & $x 00 x$ & $x x x$ & $x 0 x$ & $x 0 x$ & - & . \\
\hline 8 & \multicolumn{2}{|c|}{ Guru Ngaji Sejahtera } & $x 00$ & $x 0 x$ & $x 0 x$ & $x 00 x$ & $x 00 x$ & $x 00 x$ & - & $x 00$ & $x 00$ & $x 00$ & $x 00 x$ & $x 00 x$ & $x 00 x$ & - & 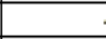 \\
\hline 9 & \multicolumn{2}{|c|}{ Tabungan Qurban } & $x 00 x$ & $x 0 x$ & $x 0 x$ & $x 0 x$ & $x 0 x$ & $x 0 x$ & - & $x 00 x$ & $x 00 x$ & $x 00$ & $x 00 x$ & $x 00 x$ & $x 00 x$ & - & 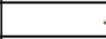 \\
\hline 10 & \multicolumn{2}{|c|}{ Tabungan Aqiqah } & $x 00$ & $x 00 x$ & $x 0 x$ & $x 00$ & $x 00 x$ & $x 0 x$ & - & $x 00$ & $x 00$ & $x 00$ & $x 00$ & $x 00 x$ & $x 00$ & - & 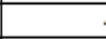 \\
\hline 11 & \multicolumn{2}{|c|}{ Wakaf Al Qur'an } & $x 00$ & $x 00 x$ & $x 00 x$ & $200 x$ & $x 00 x$ & $x 00 x$ & - & $x 00$ & $x 00 x$ & $200 x$ & $x 00 x$ & $x 00 x$ & $x 00 x$ & - & . \\
\hline 12 & \multicolumn{2}{|c|}{ Wakaf Mukenah } & $x 00 x$ & $x 00$ & $x 00$ & $200 x$ & $x 00 x$ & $x 00$ & - & $100 x$ & $x 00 x$ & $x 00$ & $x 00$ & $x 00 x$ & $x 00 x$ & - & 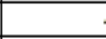 \\
\hline 13 & \multicolumn{2}{|c|}{ Peduli Bencana Alam } & $x 00 x$ & $x 0 x$ & $x 00 x$ & $x 00 x$ & $x 0 x$ & $x 00 x$ & - & $x 00 x$ & $x 00 x$ & $x 00$ & $x 00$ & $x 00 x$ & $x 00 x$ & - & 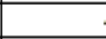 \\
\hline 14 & \multicolumn{2}{|c|}{ Segoku Segomu } & $x 00$ & $x 00 x$ & $x 00$ & $x 00 x$ & $x 00 x$ & $x 00 x$ & - & $x 00$ & $x 00 x$ & $x 00 x$ & $x 00 x$ & $x 00 x$ & $x 00 x$ & - & 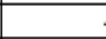 \\
\hline 15 & Siaga Covid- & & \begin{tabular}{|l|}
$x 0 x$ \\
\end{tabular} & $x 00 x$ & $x 00 x$ & $x 00 x$ & $x 00 x$ & $x 00 x$ & - & $x 00$ & $x 00 x$ & $x 00 x$ & $x 00 x$ & $x 00 x$ & $x 00 x$ & - & 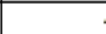 \\
\hline 16 & $\begin{array}{l}\text { Shopping } \\
\text { Bareng Yati } \\
\text { (SBY) }\end{array}$ & & $x 00$ & $x 00 x$ & $x 0 x$ & $x 00 x$ & $x 0 x$ & $x x x$ & $\cdot$ & $x 00$ & $x 0 x$ & $x 0 x$ & $x x x$ & $x 0 x$ & $x 0 x$ & - & 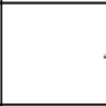 \\
\hline 17 & $\begin{array}{l}\text { Peduli } \\
\text { Aurora }\end{array}$ & & $x 0 x$ & $x 0 x$ & $x 0 x$ & $x 0 x$ & $x 0 x$ & $x x x$ & $\cdot$ & $x 0 x$ & $x 0 x$ & $x 00$ & $x x$ & $x 0 x$ & $x x$ & - & 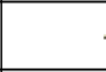 \\
\hline 18 & Paket Qurba & & \begin{tabular}{|l|l|}
$x 00$ \\
\end{tabular} & $x 00 x$ & $x 0 x$ & $x 00 x$ & $x 00 x$ & $x 0 x$ & - & $x 00$ & $x 00$ & $x 00 x$ & $x 00$ & $x 00$ & $x 00$ & - & 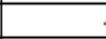 \\
\hline 19 & Santunan 10 & Muharram & $x 00$ & $x 0 x$ & $x 0 x$ & $x 0 x$ & $x x x$ & $x x x$ & - & $x 00$ & $x 00 x$ & $x 00 x$ & $x 00 x$ & $x 0 x$ & $x 00 x$ & - & 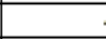 \\
\hline 20 & Bedah Rume & hustahik & $x 00$ & $x 0 x$ & $x 00 x$ & $x 0 x$ & $x 00 x$ & $x x x$ & - & $x 0 x$ & $x 00 x$ & $x 00 x$ & $x 00 x$ & $x 00 x$ & $x 00 x$ & - & . \\
\hline 21 & Santunan $\mathrm{An}$ & ak Yatim & $x 00$ & $x 00 x$ & $x 00 x$ & $x 0 x$ & $x 00 x$ & $x x x$ & - & $100 x$ & $x 00 x$ & $x 00$ & $x 00$ & $x 00 x$ & $x 00$ & - & 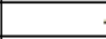 \\
\hline 22 & & & & & & & & & - & & & & & & & - & 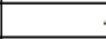 \\
\hline 23 & & & & & & & & & - & & & & & & & - & 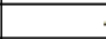 \\
\hline 24 & & & & & & & & & - & & & & & & & - & 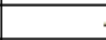 \\
\hline 25 & & & & & & & & & - & & & & & & & - & 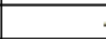 \\
\hline 26 & & & & & & & & & - & & & & & & & - & 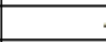 \\
\hline 27 & & & & & & & & & - & & & & & & & - & 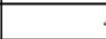 \\
\hline 28 & & & & & & & & & - & & & & & & & - & . \\
\hline 29 & & & & & & & & & - & & & & & & & - & 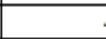 \\
\hline & & Jumlah & & & & & & & . & & & & & & & . & \\
\hline
\end{tabular}

Sumber : LAZ AZKA, diolah 


\begin{tabular}{|c|c|c|c|c|c|c|c|c|c|c|c|c|c|c|c|c|c|}
\hline & & & & & & & AFTA & R PEI & UANFAATA & N DA & NA ZISK & AF & & & & & \\
\hline & & & & & & YAY & ASAI & N AZK & A AL BAITL & UL AN & MIEN JEI & ABER & & & & & \\
\hline & & & & & & & & & TAHUN 20 & 20 & & & & & & & \\
\hline & & & & & & & & & & & & & & & & & \\
\hline & & NO.KODE & & & BUL & $\mathrm{AN}$ & & & SUB & & & $\mathrm{BU}$ & LAN & & & SUB & JUMLAH \\
\hline NO & JRAIAN & Rekening & JAN & PEB & MARA & PRRII & MEI & JUNI & JUMLAH & JULI & AGUST & SEP & ОКТОВ & NOP & DES & JUMLAH & Keseluruhan \\
\hline 1 & Zakat Maal & & $100 x$ & $x 00 x$ & $800 x$ & $x 0 x$ & $x 0 x$ & $x 0 x$ & - & $x \mathrm{xx}$ & \begin{tabular}{l|l|}
$x x x$ \\
\end{tabular} & $x 00$ & $\begin{array}{l}x 0 x \\
\end{array}$ & $x 00 x$ & $x 0 x$ & - & \\
\hline 2 & Zakat Fitrah & & $x 00 x$ & $x 00 x$ & 200 & $x 00$ & $x 00 x$ & $x 0 x$ & - & $x 00 x$ & 2000 & $x 00 x$ & $x 0 x$ & $x 0 x$ & $x 00 x$ & - & - \\
\hline 3 & Infaq dan Sha & adaqah & $x 00 x$ & $x 00$ & $x 00$ & $x 0 x$ & $x x x$ & $x 00$ & - & $x 0 x$ & $x 00 x$ & $x 00$ & $x 00$ & $x 00$ & $x 00$ & - & - \\
\hline 4 & \begin{tabular}{|l|} 
Fidyah \\
\end{tabular} & & $x 00 x$ & $x 00 x$ & $x 00 x$ & $x 00$ & $x 0 x$ & $x 0 x$ & - & $x 00 x$ & $x 00 x$ & $x 00$ & $x 0 x$ & $x 00 x$ & $x 00$ & - & - \\
\hline 5 & Dompet Dhua & & $x 00 x$ & $x 00$ & $x 00$ & $x 00$ & $x 0 x$ & $x 00 x$ & - & $x 00 x$ & $x 00 x$ & $x 00$ & $x 00 x$ & $x 00 x$ & $x 00$ & - & - \\
\hline 6 & Peduli Anak Y & Yatim & $x 00 x$ & $x 00 x$ & $200 x$ & $x 00 x$ & $x 0 x$ & $x 00 x$ & - & $x 00 x$ & $x 00 x$ & $x 00$ & $x 00 x$ & $x 00 x$ & $x 00 x$ & - & - \\
\hline 7 & Beasiswa Per & ndidikan & $x 00 x$ & $x 00 x$ & 800 & $x 00 x$ & $x 00$ & $x 0 x$ & - & $x 0 x$ & $x 00 x$ & $x 00$ & $x 00 x$ & $x 0 x$ & $x 00$ & - & - \\
\hline 8 & Guru Ngaji Se & ejahtera & $x 00 x$ & $x 00$ & $x 00$ & $x x x$ & $x 0 x$ & $x x x$ & - & $x 0 x$ & $x x x$ & $x 00$ & $x x x$ & $x 0 x$ & $x 00$ & - & - \\
\hline 9 & Tabungan Qu & urban & $x 00 x$ & $x 00$ & 200 & $x 00$ & $x 00$ & $x 00$ & - & $x 00$ & $x 00$ & $x 00$ & $x 00$ & $x 00$ & $x 00$ & - & - \\
\hline 10 & Tabungan Aq & jiqah & $x 00 x$ & $x 0 x$ & $x 00$ & $x 0 x$ & $x 0 x$ & $x 0 x$ & - & $x 0 x$ & $x 00 x$ & $x 00$ & $x 00$ & $x 00 x$ & $x 00$ & - & - \\
\hline 11 & Wakaf Al Qur & & $x 00 x$ & $x x x$ & $x 00$ & $x x x$ & $x x x$ & $x 0 x$ & - & $x 0 x$ & $x 00$ & $x 00$ & $x 0 x$ & $x x x$ & $x 00$ & - & - \\
\hline 12 & Wakaf Muken & & $x 00 x$ & $x 00$ & $x 00$ & $x 0 x$ & $x 00 x$ & $x 00 x$ & - & $x 00 x$ & $x 00 x$ & $x 00$ & $x 0 x$ & $x 0 x$ & $x 00$ & - & - \\
\hline 13 & Peduli Bencar & na Alam & $x 00 x$ & $x 0 x$ & $x 00$ & $x 00 x$ & $x 00$ & $x 00 x$ & - & $x 0 x$ & $x 00 x$ & $x 00$ & $x 00 x$ & $x 00$ & $x 00$ & - & - \\
\hline 14 & Segoku Sego & & $x 00 x$ & $x 00 x$ & $x 00 x$ & $x 00 x$ & $x 0 x$ & $x 00 x$ & - & $x 0 x$ & $x 00 x$ & $x 00$ & $x 0 x$ & $x 00 x$ & $x 00$ & - & - \\
\hline 15 & Siaga Covid-1 & & $x 00 x$ & $x 0 x$ & $x 00 x$ & $x x x$ & $x x x$ & $x x x$ & - & $x 0 x$ & $x 0 x$ & $x 00$ & $x 0 x$ & $x x x$ & $x 0 x$ & - & - \\
\hline 16 & \begin{tabular}{|l|} 
Shopping \\
Bareng Yati \\
(SBY) \\
\end{tabular} & & $x 0 x$ & $x 0 x$ & $x 0 x$ & $x 00$ & $x 0 x$ & $x 00$ & $\cdot$ & $x x x$ & $x 0 x$ & $x 00$ & $x x x$ & $x x x$ & $x 00$ & - & - \\
\hline 17 & \begin{tabular}{|l|} 
Peduli \\
Aurora \\
\end{tabular} & & $x 00$ & $x x x$ & $x 0 x$ & $x x x$ & $x x$ & $x x x$ & - & $x x x$ & $x 0 x$ & $x 00$ & $x x x$ & $x x x$ & $x 00$ & - & - \\
\hline 18 & Paket Qurbar & & $x 00$ & $x 0 x$ & $x 00$ & $x 0 x$ & $x 00$ & $x 00$ & - & $x 0 x$ & $x 00 x$ & $x 00$ & $x 00$ & $x 00$ & $x 00$ & - & - \\
\hline 19 & Santunan 10 & Muharram & $x 00 x$ & $x 00 x$ & $x 00$ & $x 00 x$ & $x 0 x$ & $x 00 x$ & - & $x 00 x$ & $x 00 x$ & $x 00$ & $x 00 x$ & $x 00$ & $x 00$ & - & - \\
\hline 20 & Bedah Rumal & h Mustahik & $x 00 x$ & $x 00 x$ & $x 00 x$ & $x 00 x$ & $x 0 x$ & $x 00 x$ & - & $x 00$ & $x 00 x$ & $x 00$ & $x 00 x$ & $x 0 x$ & $x 00 x$ & - & - \\
\hline 21 & Santunan Ana & ak Yatim & $200 x$ & 1000 & 200 & $x 00$ & $x 00 x$ & $x 0 x$ & - & $x 00 x$ & 2000 & $x 000$ & $x 00 x$ & $x 0 x$ & $x 00 x$ & - & - \\
\hline 22 & & & & & & & & & - & & & & & & & - & - \\
\hline 23 & & & & & & & & & - & & & & & & & - & - \\
\hline 24 & & & & & & & & & - & & & & & & & - & - \\
\hline 25 & & & & & & & & & - & & & & & & & - & - \\
\hline 26 & & & & & & & & & - & & & & & & & - & - \\
\hline 27 & & & & & & & & & - & & & & & & & - & - \\
\hline 28 & & & & & & & & & - & & & & & & & - & - \\
\hline 29 & & & & & & & & &. & & & & & & & - & - \\
\hline & & Jumlah & & & & & & &. & & & & . & & &. & . \\
\hline
\end{tabular}

Sumber : LAZ AZKA, diolah

Berdasar format diatas memberikan informasi laporan keuangan yang disajikan LAZ AZKA Jember belum sesuai PSAK 109, Maka dalam hal ini dilakukan pendampingan.

\section{Metode Pelaksanaan}

Berdsarkan data permasalahan itra terkait penyusunan laporan keuangan maka dilakukan tahapan pendampingan sdengan Menyusun tahapan metode penyelesaian masalah sebagai berikut:

\begin{tabular}{|c|c|c|c|}
\hline \multirow[t]{2}{*}{ NO } & \multicolumn{2}{|l|}{ Uraian } & \multirow[t]{2}{*}{$\begin{array}{l}\text { Metode penyelesaian } \\
\text { masalah }\end{array}$} \\
\hline & Masalah & Solusi & \\
\hline 1 & $\begin{array}{l}\text { Laporan keuangan } \\
\text { masih tercampur }\end{array}$ & $\begin{array}{lr}\text { Diberikan pelatihan dan } \\
\text { pendampingan } & \text { dalam } \\
\text { Menyusun } & \text { laporan }\end{array}$ & $\begin{array}{l}\text { Dibuatkan buku Saku ttg } \\
\text { Pedoman Lak Keu Zakat } \\
\text { (PSAK 109) }\end{array}$ \\
\hline
\end{tabular}




\begin{tabular}{|l|l|l|l|}
\hline & & keuangan LAZ & \\
\hline 2 & $\begin{array}{l}\text { Belum Ada laporan } \\
\text { keuangan zakat, } \\
\text { infaq, amil yang } \\
\text { sesuai standart }\end{array}$ & $\begin{array}{l}\text { Diberikan pelatihan dan } \\
\text { pendampingan dalam } \\
\text { Menyusun laporan } \\
\text { keuangan LAZ }\end{array}$ & $\begin{array}{l}\text { dibuatkan format laporan } \\
\text { keuangan Lembaga amil } \\
\text { zakat yang sederhana } \\
\text { namun memenuhi standart } \\
\text { akuntabilitas yang baik }\end{array}$ \\
\hline
\end{tabular}

\section{Hasil Dan Pembahasan}

Dalam tahap pelaksanaan program tim melakukan Analisa pelaporan dan pengelolaan keuangan yang sudah berjalan selama ini, kemudian maping permaslaah atau kelemahan yang ada untuk selanjutnya melakukan diskusi dengan pihak-pihak terkait untuk merumuskan aktivitas yang akan dijalankan berdasar hasil temuan kelemahan.

Berdasarkan hasil Analisa laporan dan pengelolaan keuangan ditemukan bahwa LAZ AZKA AL BAItul amien jember masih ada kelemahan dalam menyajikan aporan keuangan keuangan sbagaimana dalam table 1.1 sehingga dilaksanakan kegiatan pelatihan dan pendampingan penyusunan laporan keuangan oleh tim yang dilaksanakan sebanyak delapan pertemuan. Kegiatan ini berfokus dalam peningkatan akuntabilitas sitem pengelolaan dan penyusunan laporan keuangan yang sesuai standart PSAK 109.

Secara mendalam tim juga melakukan dialog dan diskusi terhadap pengelola keuangan sebagai mitra pengabdian ini, hal ini dilakukan agar mereka lebih memahami bagaimana laporan keuanganya yang akuntabel. Hal ini menarik Ketika Merika antusian bercerita kendala - kendala yang dialami selama mengelola LAZ AZKA Baitul Amin jember, Dengan demikian pelaksaan penyajian laporan keuangan yang sesuai standart PSAK 109 ini dapat memudah pengelola keuangan dalam mempertanggungjawabkan pengelolaan dana serta para pimpinan dengan mudah dapat membaca dan memahami kondisi keuangan LAZ sebagaimana laporan yang sdh tersaji.

Adapun format laporan keuangan yang ditawarkan kepada mitra adalah sebagai berikut :

1. Lapoan Posisi Keungan

2. Laporan perubahn dana

3. Laporn Aset kelolaan

4. Laporn Arus Kas

5. CALK (masih belum di implementasikan)

\section{Simpulan}

LAZ AZKA Jember telah berdiri sejak tahun 2004 dan hingga kini penyajian laporan pertanggungjwaban masih menggunakan sistem pembukuan sederhana namun tidak menjadi kendala dalam pelaksanaan program kerjanya. karena sederhananya laporan keuangan yang tersaji maka tim PKM melaukan pendampingan untuk Menyusun laporan keuangan yang sesuai dengan standart sehingga dapat memenuhi kriteria laporan keuangan yang akuntabel berdasar standart akuntansi zakat dan infaq/sedekah, yakni PSAK 109. 


\section{Daftar Pustaka}

Ikatan Akuntan Indonesia. (2011). Pernyataan Standart Keuangan Nomor 109 tentang Pelaporan Akuntansi Zakat, Infaq/Sedekah. Jakarta

Kasdi. (2016). Filantropi Islam Untuk Pemberdayaan Umat. Iqthisadia.Vol. 9 No. 2.

KMA No.581 tahun 1999 tentang Pelaksanaan Zakat

KMA No.373 tahun 2003 tentang Teknis Pengelolaan Zakat

Keputusan Direktur Jendral Bimbingan Masyarakat Islam dan Urusan Haji No.D/291/2000 tentang Teknis Pengelolaan Zakat

Martanti, Dwi. (2016). Akuntansi Keuangan Menengah Berbasis PSAK. Jakarta: Salemba Empat.

Mursyidi. (2013). Akuntansi Zakat Kontemporer, Bandung: Rosdakarya

Nahdiah, Alvin. (2016). Penerapan Akuntansi Zakat, Infak Dan Shodaqoh Pada Lembaga Amil Zakat Infaq Dan Shadaqoh Masjid Jami' AL-Baitul Amin Kabupaten Jember, Universitas Jember.

UU No. 38 tahun 1999 tentang Pengelolaan Zakat. 
Pengelolaan Keuangan Yang Akuntabel Pada Lembaga Amil Zakat Azka Jember

Munir Is'adi, Nur lka Mauliyah 